\title{
HIV/AIDS awareness in newly married females coming in OPD of a Medical College Hospital
}

\author{
Singh N. ${ }^{1}$, Chandrakar K. ${ }^{2}$ \\ ${ }^{1}$ Dr. Neelam Singh, Associate Professor, ${ }^{2}$ Dr. Kshma Chandrakar, Assistant Professor, Department of Obstetrics \& \\ Gynecology, J. K. Hospital and L.N. Medical College, Bhopal, MP, India.
}

Corresponding Author: Dr. Kshma Chandrakar, Assistant Professor, Department of Obs. \& Gynaecology J.K. Hospital and L.N. Medical College, Bhopal. Email: dr.kshmachandrakar@gmail.com

\begin{abstract}
Objective: To assess the awareness of HIV/AIDS in newly married females coming in Gynaecology OPD of a Medical College Hospital and to devise strategies for future programmes. Methodology: 11 villages and urban population around our hospital were taken for study. Newly married females coming in Gynaecology OPD for various complaints were surveyed. The females were asked to fill a pre-designed Performa, which included multiple choice questions. Results: In our study 489 patients were assessed. $65.4 \%$ women had knowledge about disease, $57.5 \%$ knew about complications of disease, $59.9 \%$ had knowledge about prevention of disease, $66.8 \%$ were aware about treatment of disease, $48.5 \%$ had knowledge about etiology of disease and 39.1\% were aware about medico legal aspect of disease. Conclusion: The study showed tremendous lacunae in awareness of HIV/AIDS. There is a need for evolving information, education, and communication strategies to focus on raising awareness on $\mathrm{RH}$ and gender related issues. A sociocultural research is needed to find the right kind of sexual health services for these young girls.
\end{abstract}

Key words: Human Immunodeficiency, STD, Attitudes, Knowledge

\section{Introduction}

The acquired immunodeficiency syndrome (AIDS) is a major emerging public health problem in India. According to an estimate made by the regional office of the World Health Organization (WHO) Southeast Asia, India accounts for over two-thirds of all human immunodeficiency virus (HIV)-infected individuals in the region [1]. Sexually active youth have been identified as a group at high risk of HIV infection. Satpathy SK, Shaukat M et al did a study on HIV/AIDS in India-The present scenario [2]. There is substantial evidence that sexually transmitted diseases (STDs) enhance the transmission and acquisition of HIV infection, and that control of STDs is helpful in preventing HIV/AIDS. Cohen MS found in his study that sexually transmitted diseases enhance HIV transmission which now is no longer a hypothesis [3].

Hence this group of sexually active young girls was taken for study and their knowledge on the subject of HIV/AIDS was assessed. Despite the fact that young females represent almost one quarter of the Indian population, their reproductive health needs are poorly understood and ill served. This paper documents the

Manuscript received: $10^{\text {th }}$ March 2018

Reviewed: $20^{\text {th }}$ March 2018

Author Corrected: $27^{\text {th }}$ March 2018

Accepted for Publication: $31^{\text {st }}$ March 2018 existing research on sexual and reproductive health, explores the knowledge and attitudes among this population in India, and highlights limitations of methodologies currently employed in research on reproductive health in India.

The social system in our country is such that stigma is attached to the word 'sex', and anything connected with sex is neither spoken loudly, nor discussed in public. Sex education has not yet been properly included in the formal educational curriculum in schools, while the reported proportion of students engaging in premarital sex varies from $8 \%$ to $15 \%$.

This combination of high-risk behavior among youth and the societal lack of communication about sexual matters is likely to be conducive to the spread of HIV infection in our country. Hence the youth and newly wed couples are the target group to raise awareness on this topic.

Our study sought to assess knowledge, attitudes and practices regarding sexuality, and the risk factors associated with the spread of HIV/ AIDS and STDs among these patients. 


\section{Methodology}

Place of study- Department of Obs. \& Gynaecology. L.N. Medical College, Bhopal (M.P.). Medical college Out patients department are ideal locations to conduct study on newlyweds as they offer the opportunity to access young people of different social backgrounds under similar circumstances. The patients were selected from different parts of city and rural areas keeping in mind that these patients will represent sample from the different religions, socio economic and family back grounds. 11 villages and urban population around the hospital were taken in study. After explaining the purpose of the study, a written consent was obtained from them

Period of study: The study was conducted over a period of 9 months from $2^{\text {nd }}$ July 2016 to $30^{\text {th }}$ March 2017

Type of study- This observational cross-sectional study HIV/ AIDS awareness in newly married females coming in OPD of a Medical College Hospital was carried out.

Inclusion criteria- The criteria of study group were taken as females having a marital life of less than one year with age group in the range of 18 to 30 years.

The patients were administered a pre-designed Performa, which included multiple choice questions. The response

\section{Original Research Article}

rate of patients was $100 \%$. Question paper was given and while collecting back it was ensured that it did not include the name of patient, so as to make her free of pressure of low score. While collecting the filled Performa it was ensured that entries were complete.

The patients were given a set of questions which shows knowledge about disease, etiology, prevention, treatment, complications and medico legal aspect of disease.

$\mathrm{K} / \mathrm{D}=$ knowledge about disease, which includes question no. $2,3,4,9,10,14,15,18,19,20,21,22,26$ and 32

$\mathrm{K} / \mathrm{C}=$ knowledge about complications, which includes question no. 5,8 and 27

$\mathrm{K} / \mathrm{P}=$ knowledge about prevention, Shown by question no. $7,13,16,17,23,25,31$

$\mathrm{K} / \mathrm{T}=$ knowledge about treatment, Judged by question no. $6,24,28,29,30,35$

$\mathrm{K} / \mathrm{E}=$ knowledge about etiology, Access by question no. $11,12,33,34$

$\mathrm{K} / \mathrm{ML}=$ knowledge about medicolegal aspect, Includes question no. $36,37,38,39$

And question no. 1 shows where from the patients came to know about HIV/AIDS

\section{Results}

From the above tables, those who came to know about HIV/AIDS from television scored well and higher than any other source of information. Books being the second most common source of knowledge. Only 25.3\% rural patients knew about mother to baby transmission while urban patients scored $53.3 \%$. Only 79\% females knew condom can prevent HIV. In our study $30 \%$ female from rural areas knew about vertical transmission and other ways of mother to baby transmission.

While in urban population $39.6 \%$ female knew about it. In our study $86.5 \%$ Rural female knew that condom can prevent HIV transmission. Only $61.5 \%$ urban female knows that there is HIV kit test available before blood transfusion. We found that females of rural areas had $76.9 \%$ knowledge about disease and $69.5 \%$ had Knowledge regarding complications of disease.

Regarding knowledge about prevention of disease, rural females scored $63.2 \%$ while urban females scored $58.7 \%$ respectively. In regards to knowledge about treatment rural females $71.5 \%$ while of urban areas female scored 66.3 . Knowledge regarding etiology rural female scored 53.8\% in comparison to urban female. Knowledge of rural female is $38.9 \%$ while that of urban are $40.7 \%$ respectively regarding medicolegal issues.

Statistical Analysis- Data was analyzed using SPSS 20 statistical package. A descriptive analysis was done on all variables to obtain a frequency distribution. The mean + SD and ranges were calculated for quantitative variables. Continuous variables were compared by the Student t test. Proportions were analyzed with the chi-square test. A P value of 0.05 or less was considered statistically significant

Table No.-1: Distribution of specific knowledge

\begin{tabular}{|c|c|c|c|c|c|c|}
\hline & KD & KC & KP & KT & KE & KML \\
\hline Score & 6846 & 1467 & 3423 & 2934 & 1956 & 1956 \\
\hline Percentage & 65.44 & 57.53 & 59.95 & 66.84 & 48.52 & 39.06 \\
\hline
\end{tabular}


Original Research Article

In our study of 489 females, it was seen that overall, they scored $65.4 \%$ in knowledge about disease, $57.5 \%$ in knowledge in complication of disease, $59.9 \%$ in knowledge about prevention of disease, $66.8 \%$ in knowledge about treatment of disease, $48.5 \%$ in knowledge about etiology of disease and $39.1 \%$ in knowledge about medico legal aspect of disease.

Table No.2: Distribution of knowledge

\begin{tabular}{|c|c|c|c|c|c|c|c|}
\hline \multirow{2}{*}{ Area } & \multirow{2}{*}{ Total } & KD & KC & KP & KT & KE & KML \\
\cline { 3 - 8 } & & Sum & Sum & Sum & Sum & Sum & Sum \\
\hline Rural & 95 & 861.0 & 142.00 & 415.0 & 410.00 & 203.0 & 141.0 \\
\hline Urban & 394 & 3619.0 & 702.00 & 1637.0 & 1551.00 & 746.0 & 623.0 \\
\hline Total & $\mathbf{4 8 9}$ & $\mathbf{4 4 8 0 . 0}$ & $\mathbf{8 4 4 . 0 0}$ & $\mathbf{2 0 5 2 . 0}$ & $\mathbf{1 9 6 1 . 0 0}$ & $\mathbf{9 4 9 . 0}$ & $\mathbf{7 6 4 . 0}$ \\
\hline
\end{tabular}

In our study there were 95 patients belonged to rural areas they scored respectively $64.7 \%$ in $\mathrm{K} / \mathrm{D}, 49.8 \% \mathrm{IN} \mathrm{K} / \mathrm{C}, 62 \%$ in $\mathrm{KP}$, $71.9 \%$ in $\mathrm{K} / \mathrm{T}, 42.7$ in $\mathrm{KE}$, and $37.1 \%$ in medico legal issues while their urban counterparts scored better than rural participants.

Table No.-3: Distribution of knowledge on first information.

\begin{tabular}{|c|c|c|c|c|c|c|c|}
\hline \multirow{2}{*}{ Mode of knowledge } & \multirow{2}{*}{ Count } & KD & KC & KP & KT & KE & KML \\
\cline { 3 - 8 } & & $\mathbf{\%}$ & $\mathbf{\%}$ & $\mathbf{\%}$ & $\mathbf{\%}$ & $\mathbf{\%}$ & $\mathbf{\%}$ \\
\hline Books & 141 & 64.7 & 56.0 & 61.2 & 72.9 & 49.3 & 44.0 \\
\hline Family & 1 & 57.1 & 33.3 & 42.9 & 33.3 & 50.0 & 25.0 \\
\hline Friend & 6 & 57.1 & 55.6 & 57.1 & 58.3 & 50.0 & 41.7 \\
\hline Internet & 32 & 62.9 & 55.2 & 55.8 & 64.1 & 47.7 & 42.2 \\
\hline News & 24 & 70.2 & 50.0 & 54.8 & 68.1 & 35.4 & 34.4 \\
\hline Neighbors & 89 & 64.9 & 62.5 & 61.0 & 69.3 & 50.8 & 39.9 \\
\hline TV & 195 & 66.2 & 57.8 & 60.1 & 62.0 & 48.7 & 35.1 \\
\hline Total & $\mathbf{4 8 9}$ & $\mathbf{6 5 . 4}$ & $\mathbf{5 7 . 5}$ & $\mathbf{5 9 . 9}$ & $\mathbf{6 6 . 8}$ & $\mathbf{4 8 . 5}$ & $\mathbf{3 9 . 1}$ \\
\hline
\end{tabular}

Most common source of knowledge are television, books and neighbor and least common are family, friend and internet.

\section{Discussion}

Despite the fact that young females represent almost one quarter of the Indian population, their reproductive health needs are poorly understood and ill served. This paper documents the existing research on sexual and reproductive health, explores the knowledge and attitudes among this population in India, and highlights limitations of methodologies currently employed in research on reproductive health in India. Rural Indians due to a poor health infrastructure and high levels of poverty and ignorance, are highly vulnerable to various health problems, especially, communicable diseases including HIV/AIDS. Our study sought to assess knowledge, attitudes and practices regarding sexuality, and the risk factors associated with the spread of HIV/AIDS and STDs among these communities.

One serious limitation is the lack of attention in almost every dimension of their reproductive health, including sexuality, reproductive morbidity, abortion-seeking and reproductive choice. What is needed is more behavioral

Obsgyne Review: Journal of Obstetrics and Gynecology research that explores the levels, patterns, and sociocultural factors underlying these patients reproductive health; assesses reproductive health needs and ways in which health and information services can be structured to respond to these needs in light of the social, cultural and economic constraints that newly married face; and explores appropriate methodological alternatives, recognizing the need for community-based research, as well as the difficulties of conducting such research under the sociocultural constraints prevailing in India.

Jejeebhoy SJ et al studied young females for sexual and reproductive behavior, this review argues for far more attention within programs to address reproductive health service and information needs. Results of this review helped point out areas where STD risk communication for these couples needs to be improved. Despite knowing that use of condoms helps protect against contracting an STD, some young couples still regard condoms primarily as an interim method of contraception before using the pill. Authors concluded that sexually transmitted diseases

Available online at: www.medresearch.in 14 | P a g e 
(STDs) are a major health problem affecting mostly young people, not only in developing, but also in developed countries[4].

Smith KP, Watkins SC et al did their study on perceptions of risk and strategies for prevention: responses to HIV/ AIDS in rural Malawi. According to qualitative interviews and observational journal accounts, HIV/ AIDS and strategies to prevent it are a frequent topic of conversation amongst married Malawians. The authors showed that the decline in perceived risk is significantly associated with declines in the behaviors that Malawians worry most about and perceptions of risk in individuals' social networks. So it is interpreted that the newly wedsare changing their behavior in ways that may reduce the spread of HIV/AIDS[5].

In a similar study Santhya KG et al also inferred that available programmatic sexual and reproductive health initiatives have focused disproportionately on the unmarried and on premarital sexual activity. Married young people have received little attention as a vulnerable group with distinct needs because marriage is assumed to be safe and because married adolescents and young people are assumed to face none of the stigma that their unmarried counterparts experience in accessing sexual and reproductive health services. Emerging evidence highlights that neither of these assumptions are tenable. Within the sub-population of young people, married young women constitute a group with distinct risks of human immunodeficiency virus and face a host of obstacles in making informed sexual and reproductive health decision[6].

In another very similar paper by Santhya KG, Jejeebhoy SJ et al on sexual and reproductive health needs of married adolescent girls, theauthorscollate available evidence on the situation of married adolescent girls and also sheds light on ways their sexual and reproductive health situation and choices differ from adult women. There is a need to raise awareness among girls, parents, teachers and community leaders, but more importantly, there is also a need to hold the government accountable for enforcing the legal age of marriage for girls. Further programmes to enhance married girls' autonomy within their marital homes and those that encourage education and generate livelihood opportunities need to be simultaneously developed [7].

Pallikadavath $\mathrm{S}$ et al did their study onHIV/AIDS in India has predominantly focused on known risk groups such as sex workers, sti clinic attendees and long-distance truck drivers.There is evidence of HIV spreading to rural areas.Men and women infected with HIV who live in rural

\section{Original Research Article}

areas were used to collect experiences of testing and treatment, the social impacts of living with HIV and differential impacts on women and men. Eight focus group discussions with groups drawn from the general population in the four villages were used to provide an analysis of community level views about HIV/AIDS[8].

Bracher $\mathrm{M}$ et al did a study on "Moving" and Marrying. They useda micro simulation model to estimate the proportions of rural Malawian brides and grooms who are already HIV positive when they marry. The authors estimated that HIV infection is present in between 13 and 20 per cent of couples. Although young women are more likely to be HIV positive than men of the same age, as a result of their low ages at marriage only around two per cent of brides are estimated to be HIV positive[9].

Nath A et al did their study on HIV/AIDS and Indian youth. While men reported contracting HIV from sex workers in the cities, women considered their husbands to be the source of their infection. Correct knowledge about HIV transmission co-existed with misconceptions. men and women tested for HIV reported inadequate counselling and sought treatment from traditional healers as well as professionals. owing to the general pattern of husbands being the first to contract HIV women faced a substantial burden. Implications for potential educational and service interventions are discussed within the context of gender and social relations[10].

Similar study was done by Tuladhar H, Marahatta R et al regarding awareness and practice of family planning methods in women attending gyne OPD at Nepal Medical College Teaching Hospital. Also in a survey by UNICEF on Young people and HIV/ AIDS. Nutshell of both programmes was that lack of awareness, permissiveness of societies for premarital or extra-marital sexual relationships, and sexual mixing patterns predispose these communities to HIV/AIDS and STD infections. There is a dire need for targeted interventions in order to curtail the increasing threat of HIV and other STDs among these vulnerable populations $[11,12]$.

Naik E, Karpur A postulated that ruralIndian tribal communities are an emerging high-risk group for HIV/AIDS. The study revealed that only $22 \%$ of adults had even heard of AIDS, and $18 \%$ knew how it is transmitted. In addition, only 5\% knew that STDs and AIDS were related to each other. AIDS awareness among women was lower compared to men (14\% vs.30\%). Regarding sexual practices, $35 \%$ of the respondents reported having had extramarital sexual encounters, with more males than females reporting extramarital affairs [13]. 
Mullany LC, Maung C also did a study on knowledge, attitudes, and practices among Burmese migrant factory workers. Responses were grouped into prevention, transmission and risk categories, and percentages answered correctly were recorded. Men consistently scored higher than women, with significant gender differences in the prevention and transmission questions. The survey reveals a significant lack of knowledge about HIV among factory workers and indicates that a subpopulation of Burmese people appears to lack the most basic information about the epidemic [14].

In a very similar study about knowledge and attitudes among STD clinic attendees in the second decade of HIV/AIDS, Rakwar J, Kidula N et al aimed to determine the knowledge and attitudes towards HIV/STDs among women attending an STD clinic by interviewing 520 randomly selected women. The quality of their knowledge of the transmission of HIV was low in spite of the fact that most respondents have heard of HIV/AIDS/ STDs.

It was concluded that there is a need for better educative effort on the modes of transmission and prevention of HIV, also in 'low risk' populations. Kunte A, Misra V et al did similar studies on HIV seroprevalence \& awareness about AIDS among pregnant women in rural areas of Pune district, Maharashtra, India. More work on this subject was done by Clark S, Bruce J et al Protecting young women from HIV/AIDS: the case against child and adolescent marriage $[15,16]$.

Add on to existing knowledge: There is a need for evolving information, education, and communication strategies to focus on raising awareness on $\mathrm{RH}$ and gender related issues. A sociocultural research is needed to find the right kind of sexual health services for young and newly married girls.

\section{Conclusion}

The most common source of information was television i.e. most accessible. But those who came to know about HIV/AIDS from books have more comprehensive knowledge. The knowledge level are lesser in females rural areas. Overall rural patients have lesser knowledge than urban. The study showed tremendous lacunae in awareness of all Reproductive Health $(\mathrm{RH})$ matters. There is a need for evolving information, education, and communication strategies to focus on raising awareness on $\mathrm{RH}$ and gender related issues. A sociocultural research is needed to find the right kind of sexual health services for young and newly married girls.

Funding: Nil, Conflict of interest: Nil Permission from IRB: Yes

\section{Original Research Article}

\section{References}

1. World Health Organization. Focus on population. environment, development. Geneva: WHO, 1995; 9:7.)

2. Satpathy SK, Shaukat M. HIV/AIDS in India-The present scenario. New Delhi, National AIDS Control Organization (NACO), Ministry of Health and Family Welfare, 1997:1-4.

3. Cohen MS. Sexually transmitted diseases enhance HIV transmission: No longer a hypothesis. Lancet 1998;351 (SuppI3):5-7)

4. Jejeebhoy SJ. Adolescent sexual and reproductive behavior: a review of the evidence from India. Social Science \& Medicine. 1998 Mar 20;46(10):1275-90.

5. Smith KP, Watkins SC. Perceptions of risk and strategies for prevention: responses to HIV/AIDS in rural Malawi. Soc Sci Med.2005Feb;60(3):649-60.

6. Santhya KG, Jejeebhoy SJ. Early marriage and HIV/AIDS: risk factors among young women in India. Economic and Political Weekly. 2007 Apr 7:1291-7.

7. Santhya KG, Jejeebhoy SJ. Sexual and reproductive health needs of married adolescent girls. Economic and Political Weekly. 2003 Oct 11:4370-7.

8. Pallikadavath S, Garda L, Apte H, Freedman J, Stones RW. HIV/AIDS in ruralIndia: context and health careneeds. J Biosoc Sci.2005Sep;37(5):641-55.

9. Bracher M, Santow G, Watkins S. "Moving" and Marrying: Modelling HIV Infection among Newly-weds in Malawi. Demographic Research. 2003 Sep 19;1: 207-46.

10. Nath A. HIV/AIDS and Indian youth-a review of the literature (1980-2008). SAHARA: Journal of Social Aspects of HIV/AIDS Research Alliance. 2009 Mar 1; 6 (1):2-8.

11. Tuladhar H, Marahatta R. Awareness and practice of family planningmethods in womenattendinggyneOPD at NepalMedicalCollegeTeaching Hospital. Nepal Med Coll J. 2008 Sep;10(3):184-91.

12. UNICEF., Joint United Nations Programme on HIV/AIDS., World Health Organization. Young people and HIV /AIDS: Opportunity in crisis. The Stationery Office; 2002. 
13. Naik E, Karpur A, Taylor R, Ramaswami B, Ramachandra S, Balasubramaniam B, Galwankar S, Sinnott J, Nabukera S, Salihu HM. Rural Indian tribal communities: an emerging high-risk group for HIV/AIDS. BMC International Health and Human Rights. 2005 Dec; $5(1): 1$.

14. Mullany LC, Maung C, Beyrer C. HIV/ AIDS knowledge, attitudes, and practices among Burmesemigrant factory workers in Tak Province, Thailand. AIDS Care. 2003Feb;15(1):63-70.

15. Rakwar J, Kidula N, Fonck K, Kirui P, NdinyaAchola J, Temmerman M. HIV/STD: the women to

\section{Original Research Article}

blame? Knowledge and attitudes among STD clinic attendees in the second decade of HIV/AIDS. International journal of STD \& AIDS. 1999 Aug;10 (8): $543-7$

16. Kunte A, Misra V, Paranjape R, Mansukhani N. HIV seroprevalence \& awareness about AIDS among pregnant women in rural areas of Pune district, Maharashtra, India. Indian Journal of Medical Research. 1999 Oct 1;110:115.

17. Clark S, Bruce J, Dude A. Protecting young women from HIV/AIDS: the case against child and adolescent marriage. International family planning perspectives. 2006 Jun 1:79-88.

\section{How to cite this article?}

Singh N, Chandrakar K. HIV/AIDS awareness in newly married females coming in OPD of a Medical College Hospital. Obs Rev:J obstet Gynecol 2018;4(1):12-17.doi: 10.17511/joog.2018.i01.03. 